\title{
Editorial
}

\section{Climate change and mental health: time for action and advocacy}

\author{
Emmet Power ${ }^{1}$ (D), Niamh McCarthy ${ }^{2}$, Ina Kelly ${ }^{3}$, Mary Cannon ${ }^{1}$ and David Cotter ${ }^{1}$ \\ ${ }^{1}$ Department of Psychiatry, RCSI University of Medicine and Health Sciences, Dublin, Ireland, ${ }^{2}$ Psychiatry of Later Life Services, St. Camillus Hospital, Limerick, \\ Ireland and ${ }^{3}$ Department of Public Health, HSE Midlands, Central Office, Dublin, Ireland
}

\begin{abstract}
Climate change poses an existential threat to our planet and our health. We explore the intersections of climate change and mental health which has been under-recognised to date. Climate change can affect mental health directly through the effects of extreme weather events such as heat, drought and flooding, and indirectly through increasing rates of migration and inequality. Vulnerable individuals with neuropsychiatric disorders will be particularly at risk. Emerging evidence is also showing effects of air pollution on brain development. Mitigation efforts related to reducing carbon emissions will have both direct and indirect effects on mental health. A further consideration demonstrated by the COVID-19 pandemic is that the spread of infectious disease can have substantial effects on the mental health of the population. With climate change and biodiversity loss, pandemics could recur in the future with increasing frequency. It is now essential that mental health professionals be equipped as agents for climate action.
\end{abstract}

Keywords: Biodiversity loss; climate change; COVID-19; mental health; psychiatry

(Received 24 September 2021; accepted 8 October 2021; First Published online 24 January 2022)

Climate change is one of the greatest threats to human existence in the 21st century. If current climate action trajectories do not improve, children born now will experience more severe and frequent health threats than their predecessors (Watts et al. 2019). Food insecurity, increasing frequency of natural disasters, extreme weather events and spread of infectious diseases are predicted to be major future challenges to public health in the face of climate change. Health services already faced with growing demographic challenges will also encounter the additive effects of climate change on service demands (Watts et al. 2019). The existence of climate change is relatively undisputed, and the lack of progress to curtail its trajectory is concerning. In this editorial, we explore the possible effects of climate change on mental health.

\section{Extreme weather events}

A growing number of studies are contributing towards an understanding of human influences on climate change and extreme weather events (Zhai et al. 2018). Berry et al. (2010) characterise these climate change-related weather events as acute, sub-acute and chronic. Examples of acute events include extreme weather events or natural disasters such as flooding, storms and hurricanes. Sub-acute events include drought and climate change-related epidemics. Chronic events include desertification, changes in ambient air temperature and rising sea levels. The effects of natural disasters on mental health include increases in a range of mental health problems. Flooding, an event we are likely to experience in

\footnotetext{
Address for correspondence: Dr E. Power, Department of Psychiatry, Royal College of Surgeons in Ireland Education and Research Centre, Beaumont Hospital, Beaumont Road, Dublin 9, Ireland. (Email: emmetpower@rcsi.com)

Cite this article: Power E, McCarthy N, Kelly I, Cannon M, and Cotter D. (2023) Climate change and mental health: time for action and advocacy. Irish Journal of Psychological Medicine 40: 6-8, https://doi.org/10.1017/ipm.2021.70
}

Ireland, comes with risks of chronic mental distress and Post Traumatic Stress Disorder (PTSD) (Jermacane et al. 2018; Munro et al. 2017; Reacher et al. 2004).

Severe storms also increase population-level mental health risks. After Hurricane Katrina, 16\% of survivors sought treatment for mental health problems in the 8 months following the hurricane and this represented just one in three of the individuals whom reported significantly elevated psychological symptoms in that same period (Wang et al. 2007). Almost one in four Hurricane Katrina survivors who were undergoing mental health treatment prior to the hurricane reduced or discontinued their treatment because of the disruption they experienced (Wang et al. 2007).

\section{Effects of heat}

Extreme heat and drought are known consequences of climate change (Dai, 2013; Di Lorenzo et al. 2010). Potential impacts may have already been seen in suicide rates in middle-aged males in rural areas of Australia that have experienced unprecedented periods of drought since the millennium (Hanigan et al. 2012). More broadly, extreme temperatures tend to have dose-response effects associated with a variety of population-level indicators of mental health including emergency presentations, mortality associated with neuropsychiatric disorders and mental health admissions (Page et al. 2007; Wang et al. 2014; Page et al. 2012). These effects are replicated across different social contexts and continents (Shiloh et al. 2005; Sung et al. 2011; Wang et al. 2018; Wang et al. 2014). There is limited understanding of the factors influencing why air temperatures are associated with increased mortality, admissions and emergency presentations of individuals living with severe mental illness. Comorbid physical illness, awareness of self-care, social isolation and inadequate housing are potential factors that could explain this relationship. There is a need for 
mental health professionals, particularly in heatwave prone countries to include this aspect of patient care in their risk assessments.

\section{Inequalities and migration}

Climate change will disproportionately affect those experiencing disadvantage whom are likely to have higher pre-existing prevalence of mental disorder. The disproportionate effects of climate change will also occur on a variety of scales, both between and within countries. Climate change will mean fewer resources in already vulnerable areas experiencing biocapacity strain, such as the Sahel region of Africa, and this is likely to lead to further armed conflict. We may expect estimated population transfers of at least 200 million people from regions with high climate change susceptibility and low climate change adaptability, such as African and South Asian river deltas (Myers, 2005). These future climate change-related migrants will have high levels of vulnerability, facing many cultural, economic and linguistic barriers (Bhugra, 2004). In Ireland, asylum seekers have 5-6 fold higher risks of mental health disorders such as depression and PTSD, compared to the general population (McMahon et al. 2007; Toar et al. 2009). Migrant status and specifically cultural distance have also been associated with increased risks of psychotic disorders (Selten et al. 2020). Despite known health risks associated with migration, few countries in the developed world have developed migrant reception procedures and services that promote optimal health and well-being. This is an area of pressing need where mental health professionals need to advocate further.

\section{Natural and built environments}

Unhealthy, air-polluted urban environments are increasingly being shown to have a negative impact on mental health (Braithwaite et al. 2019; Newbury et al. 2019). Potential mechanisms for this association such as effects of air pollution on brain inflammation and oxidative stress have been investigated in both human cohort studies and experimental animal models (Hajipour et al. 2020; Peters et al. 2019). Access to green spaces has been repeatedly associated with better mental and physical health and reduced all-cause mortality (Callaghan et al. 2021; Rojas-Rueda et al. 2019). Investments in creating safe and effective modes of active travel and mass transit and promoting increased physical exercise will help to reduce carbon emissions, particulate matter and toxin exposure and improve mental health. Active travel is an evidence-based health imperative and the medical community needs to be more effective in advancing it.

\section{Pandemics and biodiversity}

In discussing the climate crisis, we must remember that we are facing a dual crisis in the environment. We are not just faced with the threat of a warming atmosphere but also that of biodiversity loss. As humans encroach further and further into remote places of the natural world, we face increasing risks of more spill-over events from more phylogenetically distant, and therefore more potentially virulent and transmissible micro-organisms (Johnson et al. 2020). Indeed climate change is suspected to play a role in increasing bat diversity in the Chinese province of Yunnan that has been associated with the emergence of both SARS COVID 1 and 2 (Beyer et al. 2021). We have recently experienced the mental health impacts of the COVID-19 pandemic (Moreno et al. 2020). These effects have been substantial and are likely to persist for many years to come. Preventing the next pandemic by increasing early warning response systems through public health infrastructure investment is an urgent and absolute priority.

\section{Building capacity}

Mental health and public health professionals are experienced in understanding science, communicating it effectively and enabling behaviour change. Therefore, they are uniquely valuable to the climate crisis. Our role should be twofold: Reducing the impact of our activities on the environment and providing trusted, hopeful leadership to prepare for the effects of climate change on the population's mental health. The carbon footprint of healthcare accounts for $4.4 \%$ of worldwide emissions. Ireland is a major emitter and there is much we must do to reduce the impact in our domestic health sector (Karliner et al. 2019). To prepare and strengthen the healthcare system to serve the population, the focus of care must shift from an individual, illness-based model to a whole community, health-based approach including prevention and fostering of social capital, community resilience and personal empowerment (Maughan et al. 2014). Our medical and psychiatric training and curricula must also be climate proofed (Maughan et al. 2014). COVID-19 has witnessed the world looking to healthcare professionals for leadership; our clinicians must be equipped to manage this effectively. Framing the climate crisis as a health crisis is both true and necessary, with the added benefit of increasing public engagement which is crucial in building momentum to avert catastrophic climate breakdown (Myers et al. 2012).

\section{Climate grief to climate action}

Capturing the intersection of environmental change and mental health, Albrecht et al. (2007) described 'Solastalgia' (synonymous with eco-anxiety, ecological grief, climate grief and climate anxiety). This phenomenon is defined as personal distress associated with environmental change and destruction. Albrecht et al. (2007) first described this phenomenon in the drought-stricken Hunter Valley region in Australia. MacSuibhne (2009) argued that 'Solastalgia' is not yet a mental illness as it is not part of the diagnostic armamentarium of psychiatrists. Nevertheless, concepts such as climate grief have captured the public imagination through the activism of young people and, it is likely to be a term we will increasingly encounter. Climate anxiety in young people can be viewed as a response to an impending major crisis in which those most affected by threat have the least agency to enforce change. Beyond recognising the threat, health professionals should promote acceptance of the seriousness of climate change and endorse value-based actions to help everyone in society live more sustainable lives (Wu et al. 2020). The existence of organisations such as Irish Doctors for the Environment (www.ide.ie) and leadership from the World Health Organisation are hopeful signs that the medical profession is mobilising to address the climate crisis (WHO, 2017). There is little time to waste in promoting action. Every degree of warming counts.

Conflicts of interest. The authors have no conflicts of interest to declare.

Ethical standards. The author asserts that all procedures contributing to this work comply with the ethical standards of the relevant national and institutional committee on human experimentation with the Helsinki Declaration of 1975, as revised in 2008 .

Financial support. Health Research Board 'YouLead' Collaborative Doctoral Award (grant code 18210A01) supports EP. European Research Council Consolidator Award (Grant code 724809 iHEAR) supports MC. Health 
Research Board ILP POR 2017-039 and Health Research Board ILP POR 20190005 support DC.

\section{References}

Albrecht G, Sartore GM, Connor L, Higginbotham N, Freeman S, Kelly B, Stain H, Tonna A, Pollard G (2007). Solastalgia: the distress caused by environmental change. Australasian Psychiatry 15, S95-S98.

Berry HL, Bowen K, Kjellstrom T (2010). Climate change and mental health: a causal pathways framework. International Journal of Public Health 55, 123-132.

Beyer RM, Manica A, Mora C (2021). Shifts in global bat diversity suggest a possible role of climate change in the emergence of SARS-CoV-1 and SARS-CoV-2. The Science of the Total Environment 767, 145413.

Bhugra D (2004). Migration and mental health. Acta Psychiatrica Scandinavica 109, 243-258.

Braithwaite I, Zhang S, Kirkbride JB, Osborn DP, Hayes JF (2019). Air pollution (particulate matter) exposure and associations with depression, anxiety, bipolar, psychosis and suicide risk: a systematic review and metaanalysis. Environmental Health Perspectives 127, 126002.

Callaghan A, McCombe G, Harrold A, McMeel C, Mills G, Moore-Cherry N, Cullen W (2021). The impact of green spaces on mental health in urban settings: a scoping review. Journal of Mental Health 30, 179-193.

Dai A (2013). Increasing drought under global warming in observations and models. Nature Climate Change 3, 52-58.

Di Lorenzo E, Cobb KM, Furtado JC, Schneider N, Anderson BT, Bracco A, Alexander MA, Vimont DJ (2010). Central Pacific El Niño and decadal climate change in the North Pacific Ocean. Nature Geoscience 3, 762-765.

Hajipour S, Farbood Y, Gharib-Naseri MK, Goudarzi G, Rashno M, Maleki H, Bakhtiari N, Nesari A, Khoshnam SE, Dianat M, Sarkaki A (2020). Exposure to ambient dusty particulate matter impairs spatial memory and hippocampal LTP by increasing brain inflammation and oxidative stress in rats. Life Sciences 242, 117210.

Hanigan IC, Butler CD, Kokic PN, Hutchinson MF (2012). Suicide and drought in New South Wales, Australia, 1970-2007. Proceedings of the National Academy of Sciences of the United States of America 109, 1395013955.

Jermacane D, Waite TD, Beck CR, Bone A, Amlôt R, Reacher M, Kovats S, Armstrong B, Leonardi G, Rubin GJ, Oliver I (2018). The English National Cohort Study of Flooding and Health: the change in the prevalence of psychological morbidity at year two. BMC Public Health 18, 330.

Johnson CK, Hitchens PL, Pandit PS, Rushmore J, Evans TS, Young CC, Doyle MM (2020). Global shifts in mammalian population trends reveal key predictors of virus spillover risk. Proceedings of the Royal Society $B$ 287, 20192736.

Karliner J, Slotterback S, Boyd R, Ashby B, Steele K (2019). Health Care's Climate Footprint. How the Health Sector Contributes to the Global Climate Crisis and Opportunities for Action. Health Care Without Harm: Reston, VA (https://noharm-global.org/sites/default/files/documents-files/5961/ HealthCaresClimateFootprint_092319.pdf). Accessed 24 September 2021.

MacSuibhne SP (2009). What makes "a mental illness"? What makes "a new mental illness"?: The cases of solastalgia and hubris syndrome. Cosmos and History: The Journal of Natural and Social Philosophy 5, 210-225.

Maughan D, Berry H, Davison P (2014). What psychiatrists should know about environmental sustainability and what they should be doing about it. International Psychiatry 11, 27-30.

McMahon J, MacFarlane AE, Avalos G, Cantillon P, Murphy AW (2007). A survey of asylum seekers' general practice service utilisation and morbidity patterns. Irish Medical Journal 100, 461-464.

Moreno C, Wykes T, Galderisi S, Nordentoft M, Crossley N, Jones N, Cannon M, Correll CU, Byrne L, Carr S, Chen EY (2020). How mental health care should change as a consequence of the COVID-19 pandemic. The Lancet Psychiatry 7, 813-824.

Munro A, Kovats RS, Rubin GJ, Waite TD, Bone A, Armstrong B, Beck CR, Amlôt R, Leonardi G, Oliver I (2017). Effect of evacuation and displacement on the association between flooding and mental health outcomes: a cross-sectional analysis of UK survey data. The Lancet Planetary Health $\mathbf{1}$, e134-e141.

Myers N (2005). Environmental refugees: An emergent security issue; Documents from the 13th Economic Forum. In: Proceedings of the 13th Meeting of the Organization for Security and Co-operation in Europe (OSCE) Economic Forum, Session III (Environment and Migration) (https://www.osce.org/eea/14851). Accessed 24 September 2021.

Myers TA, Nisbet MC, Maibach EW, Leiserowitz AA (2012). A public health frame arouses hopeful emotions about climate change. Climatic Change 113, 1105-1112.

Newbury JB, Arseneault L, Beevers S, Kitwiroon N, Roberts S, Pariante CM, Kelly FJ, Fisher HL (2019). Association of air pollution exposure with psychotic experiences during adolescence. JAMA Psychiatry 76, 614-623.

Page LA, Hajat S, Kovats RS (2007). Relationship between daily suicide counts and temperature in England and Wales. The British Journal of Psychiatry 191, 106-112.

Page LA, Hajat S, Kovats RS, Howard LM (2012). Temperature-related deaths in people with psychosis, dementia and substance misuse. The British Journal of Psychiatry 200, 485-490.

Peters R, Ee N, Peters J, Booth A, Mudwa I, Anstey KJ (2019). Air pollution and dementia: a systematic review. Journal of Alzheimer's Disease 70, S145-S163.

Reacher M, McKenzie K, Lane C, Nichols T, Kedge I, Iversen A, Hepple P, Walter T, Laxton C, Simpson J (2004). Health impacts of flooding in Lewes: a comparison of reported gastrointestinal and other illness and mental health in flooded and non-flooded households. Communicable Disease and Public Health 7, 39-46.

Rojas-Rueda D, Nieuwenhuijsen MJ, Gascon M, Perez-Leon D, Mudu P (2019). Green spaces and mortality: a systematic review and meta-analysis of cohort studies. The Lancet Planetary Health 3, e469-e477.

Selten JP, Van Der Ven E, Termorshuizen F (2020). Migration and psychosis: a meta-analysis of incidence studies. Psychological Medicine 50, 303-313.

Shiloh R, Shapira A, Potchter O, Hermesh H, Popper M, Weizman A (2005). Effects of climate on admission rates of schizophrenia patients to psychiatric hospitals. European Psychiatry 20, 61-64.

Sung TI, Chen MJ, Lin CY, Lung SC, Su HJ (2011). Relationship between mean daily ambient temperature range and hospital admissions for schizophrenia: results from a national cohort of psychiatric inpatients. Science of The Total Environment 410-411, 41-46.

Toar M, O'Brien KK, Fahey T (2009). Comparison of self-reported health \& healthcare utilisation between asylum seekers and refugees: an observational study. BMC Public Health 9, 214.

Wang PS, Gruber MJ, Powers RE, Schoenbaum M, Speier AH, Wells KB, Kessler RC (2007). Mental health service use among Hurricane Katrina survivors in the eight months after the disaster. Psychiatric Services 58, 14031411.

Wang S, Zhang X, Xie M, Zhao D, Zhang H, Zhang Y, Cheng Q, Bai L, Su H (2018). Effect of increasing temperature on daily hospital admissions for schizophrenia in Hefei, China: a time-series analysis. Public Health 159, $70-77$.

Wang X, Lavigne E, Ouellette-Kuntz H, Chen BE (2014). Acute impacts of extreme temperature exposure on emergency room admissions related to mental and behavior disorders in Toronto. Canada Journal of Affective Disorders 155, 154-161.

Watts N, Amann M, Arnell N, Ayeb-Karlsson S, Belesova K, Boykoff M, Byass P, Cai W, Campbell-Lendrum D, Capstick S, Chambers J (2019). The 2019 report of The Lancet Countdown on Health and Climate Change. The Lancet 394, 1836-1878.

World Health Organization (2017). Environmentally sustainable health systems: a strategic document (No. WHO/EURO:2017-2241-41996-57723) World Health Organization. Regional Office for Europe (https://apps. who.int/iris/handle/10665/340375) Accessed 24 September 2021.

Wu J, Snell G, Samji H (2020). Climate anxiety in young people: a call to action. The Lancet Planetary Health 4, e435-e436.

Zhai P, Zhou B, Chen Y (2018). A review of climate change attribution studies. Journal of Meteorological Research 32, 671-692. 